\title{
RESABIOS COLONIALES FRENTE AL SIGLO XXI
}

\author{
Etnocentrismo, racismo \\ y marginación
}

\section{Imelda Vega-Centeno B.}

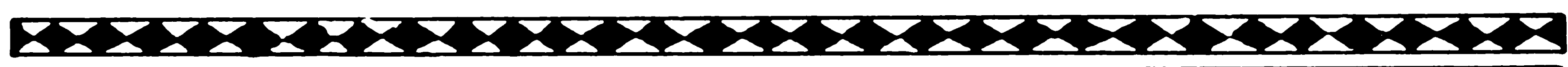

EN E MUNDO ACTUAL, los temas de la exclusión y el racismo son de una urgencia angustiante ${ }^{1}$. En la civilizada Europa han surgido diversos movimientos neofascistas que desarrollan una gran agresividad frente al extranjero, en particular si sus características físicas son notoriamente diferentes -como los norafricanos, asiáticos y centroafricanos- $y$, peor aún, si su presencia es muy notoria en términos cuantitativos. Se les percibe entonces como a invasores, cuya presencia atenta contra el ansiado bienestar de todos.

Retiene nuestra atención, en este sentido, un notable artículo de María Valdés (1993), donde la autora busca interpretar en una perspectiva antropológica las «nuevas formas de marginación» que se están produciendo en el Primer Mundo, por el hecho de tener ahora "al Tercer Mundo en casa», como producto de las incontenibles $y$ diversas migraciones que atrajeron

1 Una primera versión de este trabajo fue presentada en el Coloquio de SCOLAS: Latinoamérica ante el Sigho XXI, GuadalajaraJalisco, México, marzo de 1994. 


\section{IMELDA VEGA-CENTENO}

hacia Europa a millones de «diferentes». Seguiremos la trayectoria de su análisis, pero aplicándolo a nuestro país. Haremos entonces algunas reflexiones teóricas en torno al fenómeno sociológico de la exclusión, tal como se produce en nuestra sociedad nacional frente a las poblaciones indígenas, es decir, frente a aquellos que son los dueños de estas tierras, y que hoy, eufemísticamente, llamamos «minorías étnicas». Por otro lado, hablaremos de la forma cómo este complejo fenómeno de la exclusión nutrido de argumentos raciales, tiende a ser reproducido bajo diversas modalidades en nuestros comportamientos frente a los diferentes, a aquellos cuya cuestionadora presencia nos hace conscientes de la precariedad de nuestras seguridades culturales.

\section{Las Culturas frente a «Los Otros»}

Existe un abanico infinito de culturas, pueblos, tribus, áreas culturales, etnias y etnicidades, y esta realidad antropológica ha planteado a la humanidad, desde el inicio de los tiempos, el problema de aceptarnos diferentes. Las dificultades de la humanidad para con-vivir tienen, por eso, una larga historia. Nos-otros siempre seremos la suma de ego, los iguales a ego, más los otros como ego. Pero como cada grupo humano vive dentro de aquello que se llaman «los universos finitos de sentido" -esta es otra definición de cultura- nos es sumamente difícil reconocer los límites y posibilidades de esta finitud de sentidos, por eso es más simple vivirlos como oposición.

Los comportamientos excluyentes son productos culturales, pero, como la problemática teórica en torno a la cultura es muy compleja, nos acercaremos a ella siguiendo el recorrido propuesto por M. Valdés (1993); tomando como punto de partida a Tylor (1977), para quien: 
RESABIOS COLONIALES FRENTE AL SIGLO XXI

"Cultura, en su amplio sentido etnográfico es ese complejo conjunto que incluye las creencias, las artes, la tecnología, la moral, las leyes, las costumbres, y cualesquiera otras aptitudes $y$ hábitos adquiridos por el hombre como miembro de una sociedad» (p. 19).

La cultura es patrimonio de todos los seres humanos $y$ no de unos pocos excepcionales, se trata del conjunto de comportamientos, prácticas, sentidos y símbolos, producidos y adquiridos por un pueblo en su lucha por dominar el medio y construir lo social. Este capital cultural (Bourdieu, 1971) es transmitido de generación en generación, sin que esta transmisión signifique limitación a la innovación o anulación de la creatividad de sus miembros. Por esta razón Boas (1940) incluye el concepto de «relativismo cultural», el mismo que «debería ser la meta suprema que nos permitiría no sólo ver a los pueblos desde su propia perspectiva, sino también vernos a nosotros mismos como los otros nos vens (lb.).

Los comportamientos $y$ actitudes frente al diferente han marcado desde siempre la historia de la humanidad: los pueblos delimitaron sus fronteras por la exacerbación de sus diferencias, «el extranjero es el hombre que no es de la tribu, por eso es un enemigo potencial» (Barth, 1976). Combatir al extranjero para poder ampliar las propias fronteras es el origen de la guerra desde las sociedades primitivas, y lo es aún hoy.

\section{Del Etnocentrismo al Sociocentrismo}

El principio antropológico en el que se basa el etnocentrismo tiene su origen en las pautas culturales de los grupos primitivos, que consideran a estas pautas como las únicas posibles, las mejores, las más bellas, es 


\section{IMELDA VEGA-CENTENO}

decir, ellos mismos se perciben como excelentes. Por eso el término con que se llaman a sí mismos es, general y simplemente, el de hombres.

Damos solamente dos ejemplos del Perú. Encontramos que, en el quechua-inca, el término con que se denominan a sí mismos los quechuas, runa, quiere decir hombre; los españoles o los mestizos son los mistis, es decir, "señores", pero de una forma que no implica señorío y que puede ser despectiva. Otro caso es el de una lengua amazónica actual. En la tribu de los shipibos, shipibo quiere decir hombre, y ellos mismos son los shipibo. Por eso, a una tribu vecina más pequeña con la que entraron desde antiguo en relaciones exogámicas, la denominan los shipibo-conibo, es decir, los hombres-igual-que-yo.

Pero cuando este tipo de relación exogámica no se produce, los "otros" serán los malos, perversos, los no-hombres. Esta percepción se refleja aún en la nomenclatura con que nosotros, científicos sociales, nos referimos por ejemplo a los esquimales; éste último es un término de los algoquinos, quienes perciben a los habitantes de las zonas heladas como los «comedores de carne crudan, al igual que ciertos animales.

Todo este preámbulo es útil para señalar que la tendencia a definir las diferencias en términos de oposición valorativa es una tendencia presente en todas las culturas, las que de esta manera se refugian en el etnocentrismo como forma de protección frente a las propias carencias que les recuerda el «diferente». Satanizando al "otro" pueden olvidarse de la dominación que surge de las propias inseguridades, evidenciadas por la presencia del distinto, y refugiarse en la propia excelencia simbólica $\mathrm{u}$ objetiva, presente en la capacidad mítica, como último refugio ante la amenaza que perciben de fuera, del "otro» (Vega-Centeno, 1991).

Actualmente no utilizamos términos tan crudos como los empleados por los algoquinos para expresar 


\section{RESABIOS COLONIALES FRENTE AL SIGLO XXI}

nuestros temores frente a la diferencia, pero manifestamos abiertamente nuestro sociocentrismo -que es el etnocentrismo de las sociedades complejas- poniendo en evidencia nuestra necesidad de preeminencia, motejando, burlándonos de los «otros». Agredimos verbalmente a los otros, pero sobre todo a los más cercanos, a los que marcan nuestras fronteras, los que señalan los límites de la finitud de nuestros universos de sentido; éstos ya no serán iguales a nosotros, sino cholos, charapas, monos, gauchos, gringos, chapetones, charros, guasos, etc.

La conciencia sociocéntrica implica la incapacidad de descentramiento en una sociedad, la incapacidad de ésta para percibirse de otra forma que como centro del mundo. El grupo sociocéntrico, se percibe a sí mismo como el único modelo social válido, por ello genera la imposibilidad cultural de percibir a los otros como ellos son, proponiéndose, consciente $e$ inconscientemente, como modelo único para la humanidad entera, y proponiendo a lo propio como lo único válido en la forma de realización social $e$ individual.

Estos fenómenos sociocéntricos se dan en pequeña y gran escala, desde el sentirse «centro del mundo", complejo sociocéntrico de las ciudades donde se desarrollaron grandes civilizaciones: Roma, Milán, Tenostitlán, Cusco o Sri Lanka (Vega Centeno, 1993). Así ocurre en las complejas sociedades postindustriales occidentales, que perciben al modelo capitalista en su versión de democracia liberal, como la única forma de vida válida para toda la humanidad, sin matices.

\section{Desde la Xenofobia hasta la Xenofula}

A medio camino, entre el etnocentrismo primitivo y las complejas formas de sociocentrismo, encontramos dos fenómenos de comportamiento social frente al diferente: 


\section{IMELDA VEGA-CENTENO}

la xenobofia y la xenofilia. Estas son dos posibles variaciones de eje en la actitud etnocéntrica frente al extraño, frente al que tiene características físicas $y / 0$ culturales diferentes.

La xenofobia es la aversión al extranjero, la misma que implica una jerarquización de culturas en la cual la propia ocupa un lugar superior incuestionable; estos son los fundamentos de todos los proyectos de expansión colonial y de la intervención de unos en la historia $y$ territorios de otros pueblos. Se hagan a nombre de la Cruz, de la pureza de la raza, de la defensa del occidente o de «la civilización», la colonización y la moderna intervención militar están preñadas de contenidos xenófobos. La xenofobia está en el origen de todas las guerras internacionales $y$ de las guerras civiles, como las actuales en la ex-Yugoeslavia, en Ruanda o Somalia. Más cerca, la xenofobia está presente, además, en la forma cómo se reprime al campesinado en toda América Latina.

Por su parte, la xenofilia es el fenómeno opuesto a la xenofobia. Aquí se percibe a la propia cultura como inferior a la cultura del extranjero; esta actitud implica el desprecio de lo propio y la fascinación por lo ajeno, lo que se expresa a través del mimetismo cultural. Este último comportamiento es muy peligroso, puesto que es imposible la identificación total con el extranjero, percibido como superior; por ello, en su carrera mimética, los miembros de la cultura percibida como inferior corren el riesgo de caer en la anomia cultural -pérdida de la propia cultura, sin alcanzar la deseada-, con devastadores efectos para la supervivencia del grupo.

Por otro lado, la xenofilia es un fenómeno excluyente, no admite como superiores a todos los extranjeros, sino sólo a alguno que quiere igualar; por ello aborrece a aquellos a los que el modelo supuestamente superior también aborrece. Ejemplos de esta 
actitud son el Japón de la post-guerra, mimetizado con el norteamericano vencedor, o el mimetismo de amplios sectores populares con los usos xenófobos de las clases altas en América Latina, particularmente frente al afroamericano y a los indígenas.

\section{RACISMO Y MARGINACIÓN}

Dentro del amplio margen de actitudes frente al diferente, existen otras formas complejas con que se reviste la exclusión en nuestras sociedades. Primeramente encontramos al racismo, que tal como lo define LeviStrauss (1951-1979, 1986), es la aversión no a un individuo, sino a sociedades enteras.

El racismo destructor, concatena cuatro ideas clave: primero encuentra una correlación entre el patrimonio genético, las capacidades intelectuales, y las disposiciones morales; segundo, este patrimono genético, sería compartido por todos los miembros de determinados grupos humanos; tercero, estos grupos vendrían a ser las razas, las mismas que se podrían jerarquizar en función de su patrimonio genético (vg. primera idea clave); y cuarto, estas diferencias jerárquicas autorizarían a las "razas superiores» a dominar, explotar y hasta destruir, a las consideradas urazas» inferiores (Aranzadi, 1991).

Según Aranzadi, la concatenación de estas cuatro "claves» equívocas del racismo es la que construye el "etnocentrismo jerárquico dominador», el mismo que puede llevar a holocaustos como el judío. En la actualidad, tanto los estudios biológicos como los antropológicos y de bioética, han llegado a concluir sobre la existencia de un único grupo humano, sin diferencias biológicas, intelectuales o tendencias psicosociales significativas. Entre los homo-sapiens existe una sola «raza», la raza humana. 


\section{IMEIDA VEGA-CENTENO}

En general, se tiende a considerar al racismo como producto de los procesos coloniales, los mismos que bajo la pretensión de universalismo de determinadas culturas justificaron el atropello de otras culturas con ideologías religiosas, basadas éstas en la revelación de un sólo dios a un sólo pueblo. Con estos fundamentos "revelados», se sintieron llamados a expandir por medio de una "guerra santa» el único modelo de civilización pretendidamente apto para todo el mundo. Este es el origen del expansionismo cultural de occidente.

Actualmente el racismo encuentra nuevas razones de supervivencia, en base a la función de las mal llamadas urazas» dentro del único modelo de economía de mercado (Wallerstein, 1991), o a través de un sistema selectivo meritocrático dentro de sociedades profundamente desigualitarias, donde -obviamente- sólo algunos podrán ser reconocidos por sus capacidades y méritos personales. En este sentido, el racismo produce la etnización de la exclusión (De la Cadena, 1991), tal como está planteada por el sistema economicista meritocrático individualista; llegándose a formulaciones $\tan$ an-humanas como la de «humanidad sobrante» o "población excedente», en base a las cuales se están realizando verdaderos etnocidios, tecnocráticamente justificados (vg., las políticas internacionales frente a las guerras tribales, la sequía y el avance del SIDA en el Africa).

En esta perspectiva, la marginación es el correlato necesario del racismo, y el racismo es la doctrina de la segregación. En las sociedades desigualitarias y en las relaciones internacionales asimétricas, a través de la discriminación se generan grupos que son llamados minorías, los mismos que quedan marginados de las formas de vida socialmente aceptables, reducidos a condiciones de vida éticamente injustificables. Son las «minorías» las que viven en formas precarias $y$ que no 


\section{RESABIOS COLONIALES FRENTE AL SIGLO XXI}

encuentran espacio de realización dentro del funcionamiento de la sociedad nacional, ni del sistema de globalización mundial; pues, justamente, el funcionamiento óptimo de los mismos, los aísla, arrincona $y$ embrutece, es decir, los invalida como ciudadanos de la ciudad futura.

La única forma de combatir esta marginación es la lucha contra la discriminación, la lucha por el derecho a la diferencia como pueblo, la lucha por la igualdad ante la ley. Todo lo cual implica, contradictoriamente, llevar hasta sus últimas consecuencias la lógica del universalismo, es decir, exigir la vigencia plena de la doctrina de los Derechos Humanos.

Sin embargo, para las supuestas «minorías étnicas», para los marginados en general, existe la posibilidad de que, al combatir y reivindicar sus derechos, resulten ahondando -ellos mismos- el abismo entre los marginados y los que gozan de todas las oportunidades. Pero esta es la única manera de combatir, por ejemplo, el estigma de la etnificación de las fuerzas de trabajo; marginación que nos resulta tan "natural» que decimos: "he trabajado como un negro» o «necesito cholo barato», así como en Alemania se dice respecto de alguna tarea pesada: "es trabajo para turco». El racismo y la marginación son actitudes ante la diferencia que producen la exclusión del "otro», y son características de la moderna sociedad occidental. El racismo «naturaliza, biologiza» lo social, es decir, otorga a las actitudes frente al "diferente» unos fundamentos que están más allá de la voluntad humana. La marginación se ampara en argumentos pretendidamente uracionales $y$ técnicos», y permite al sistema socioeconómico excluyente utilizar -de acuerdo a sus necesidades de ganancia- a los indigentes. Es decir, la marginación recrea y confirma en la sociedad la existencia de ciudadanos de primera clase y los de «la ínfima», como se dice aún en ciertos sectores sociales limeños. 


\section{IMELDA VEGA-CENTENO}

El racismo y la marginación de hoy reactivan los sentimientos que produjeron, desde siempre, las guerras contra el diferente, la fobia contra el otro, la agresión al extranjero y las guerras religiosas desde hace más de treinta siglos.

\section{Conclusiones Provisionales de una Replexión en Voz} AltA

En el Perú de hoy, el racismo y la marginación son prácticas sociales de exclusión que nos resultan casi naturales; sin embargo, los "diferentes» aquí resultan ser los indígenas, los ancestrales dueños del país. Hace mucho más de un siglo que no somos colonia, pero discriminamos al indígena con las mismas justificaciones coloniales pretendidamente universalistas que alentaron la xenofobia y la xenofilia de invasores $e$ invadidos de hace cinco siglos, $y$ que hoy nos caracterizan como comunidad nacional. Ya no argumentamos esta exclusión con las debilidades de la fundamentación unaturalista» decimonónica, sino a través de la autoridad "biológico-cientificista» de argumentos pretendidamente técnicos y «modernos».

En los últimos catorce años hemos vivido una experiencia de exterminio, donde en nombre de un "pensamiento guía" se pretendió someter al país a la iluminación de uno sólo. La intolerancia senderista sometió al país a sangre y fuego, con un belicismo que se caracterizó por sus contenidos xenófobos. Desgraciadamente, para combatir esta guerra contra el pueblo, las fuerzas armadas usaron los mismos argumentos de fuerza del grupo terrorista que debían combatir. Enfrentamiento sangriento e inútil que comprometió al país en una guerra fratricida, que se expresó, también, como fobia a los diferentes. 
RESABIOS COLONIALES FRENTE AL SIGLO XXI

Entre 1983 y 1989, ser joven, cobrizo, pobre, desempleado o estudiante significó un riesgo de muerte, sin tener en cuenta que esta descripción corresponde a más del cincuenta por ciento de la población nacional (Vega-Centeno, 1985). Hasta se inventó un neologismo: "los ayacuchos", para designar a aquellos que había que exterminar en nombre de la paz (L. Rachitov, citado por Flores Galindo, 1991).

Después de casi veintisietemil muertos en una absurda guerra contra el pueblo pobre, hemos querido contribuir a la toma de conciencia de la existencia y persistencia del etnocentrismo y del racismo en nuestro país, en sus diversas y actuales expresiones excluyentes. El único modo de combatir a estos nefastos resabios coloniales, que nos incapacitan para asumir la construcción del futuro, es conocerlos, reconocerlos, ponerlos en evidencia en toda su inhumanidad, para poder erradicarlos de nuestra cultura. Esta es nuestra contribución a la reconciliación de todos los peruanos con su propia historia, con todas sus sangres.

Lima, mayo de 1994. 


\section{Referencias bibliográficas}

ARANZad, J. 1991

Racismo y piedad. Reflexiones sobre un judío y un chimpancé; En: Claves de la razón práctica $\mathrm{N}^{\circ} 13$. Madrid, pp. 2-12.

BARTH, F., (COMP).

1976 Los grupos étnicos y sus fronteras: La organización social de las diferencias culturales. FCE editores, México.

BASTIDE, R.

1993

El projimo y el extraño: el encuentro de las civilizaciones. Amorrortu edts. Buenos Aires.

BOAS, $F$.

1940

The limitations of de Comparative method in Anthropology, (1896). En: Race, BOURDIEU, P. language and Culture. New York.

Genése et structure du champ religieux. En: Revue Française de Sociologie, Vol. $\mathrm{XXI}$. 
RESABIOS COLONIALES FRENTE AL SIGLO XXI

De la Cadena, Marisol

1991 Las mujeres son más indias: Etnicidad y género en una comunidad del Cusco; en: Revista Andina No17, Año 9, No1. CERA Bartolomé de las Casas, Cusco.

Flores Galndo, Alberto

1991 Tiempo de Plagas, Instituto de Apoyo Agrario Edts., Lima.

LEIRIS, $M$.

1988

Cing études d'éthnologie. Gallimard ed., Paris.

Levi Strauss, C.

1979 Raza e Historia, en: Antropología estructural (2): mito. sociedad, humanidades. Siglo XXI edts., México.

1986 Raza y cultura, en: Mirando a lo lejos, Emecé edts., Buenos Aires.

STOLCKE, V.

1988

El poder del Estado en la creación de las minorías, en: Márgenes: encuentro y Debate $N^{\circ} 4$. SUR, Casa de estudios del Socialismo, Lima. pp. 151-156.

TODOROV, T. (COMP.)

1988 Cruce de culturas y mestizaje cultural, Eds. Júcar, Madrid.

1989

Nous et les autres: Réflexion française sur la diversité humaine. Eds. du Seuil, Paris. 


\section{IMELDA VEGA-CENTENO}

TYLOR, E.B.

1977 Cultura primitiva (Los orígenes de la cultura, 1871). Eds. del Ayrusco, Madrid.

VALDÉS, María

1992-93 Inmigración y racismo: aproximación conceptual desde la Antropología, en: Boletín Americanista, $\mathrm{N}^{\circ}$ 42-43. Universidad de Barcelona, Año XXXIII, Barcelona.

VeGa-Centeno, I.

1985

América Latina: es peligroso ser joven, en: Informativo católico latinoamericano. Boletín: $N^{\circ}$ 87. SLA MIEC-JECI, Lima, abril.

1988

Ser joven y mestizo: Crisis cultural $y$ crisis social en el Perú, en: Márgenes: encuentro y debate, $\mathrm{N}^{\circ} 3$, SUR, Casa de estudios del Socialismo, Lima.

1991 Aprismo Popular: Cultura, religion y política. CISEPA-PUC y TAREA, coeditores, Lima.

WaLlerstein, I. y BaLvar, E.

1991 Raza, nación y clase, Eds. Iepala, Madrid, 1991, pp. 2-12. 